\title{
Novel Reactive Distillation-Pervaporation Coupled Process for Ethyl Acetate Production with Water Removal from Reboiler and Acetic Acid Recycle
}

\author{
Bida Lv, Gongping Liu, Xueliang Dong, Wang Wei, and Wanqin Jin* \\ State Key Laboratory of Materials-Oriented Chemical Engineering, Nanjing University of Technology, 5 Xinmofan Road, Nanjing \\ 210009, People's Republic of China
}

\section{Supporting Information}

ABSTRACT: Ethyl acetate (EtAc) is an essential raw material widely used in the chemical industry. In this paper, a new reactive distillation ( $\mathrm{RD}$ )-pervaporation (PV) coupled process for ethyl acetate (EtAc) production is proposed, in which the PV membrane is located in the bottom stream in order to selectively remove the water from the reboiler and recycle the acetic acid (HAc) into the feed. The main operating conditions of the RD process are discussed by experimental and simulation methods. The RD-PV coupled process was established by coupling the PVA/ceramic composite membrane with the RD reboiler. The effects of PV operating temperature and $\mathrm{HAc}$ /ethanol molar ratio on the $\mathrm{RD}$ performance are thoroughly discussed. It was found that the PVA/ceramic composite membrane exhibited good PV performance and stability with a total flux of $600 \mathrm{~g} \cdot \mathrm{m}^{-2} \cdot \mathrm{h}^{-1}$ and a separation factor of 14 in $90 \mathrm{wt} \% \mathrm{HAc} /$ water solution at $70^{\circ} \mathrm{C}$. Owing to the water removal and HAc recycle from the reboiler via PV, both the ethanol conversion and EtAc purity are remarkably improved, from 82.4 to 85.6 wt \% and from 81.3 to $84.8 \%$, respectively. This new $\mathrm{RD}-\mathrm{PV}$ coupled process can be expected to be an effective and energy-saving way for ethyl acetate production.

\section{INTRODUCTION}

Ethyl acetate (EtAc) is an essential raw material widely used in the chemical industry including in paints, coatings, perfumes, and adhesive agents. ${ }^{1-3}$ EtAc is mainly produced industrially via a classical esterification process in which acetic acid (HAc) and ethanol $(\mathrm{EtOH})$ react in the presence of a strongly acidic catalyst in a reactor. ${ }^{4}$ In 2001, the international market demand for EtAc was 1.0 million tons, and the demand reached 2.5 million tons in 2008. In working toward the elimination of toxic solvents, the consumption of EtAc is expected to grow at a rapid pace because of its low health and environmental effects. ${ }^{3}$

For reversible reactions such as esterification and etherification, the equilibrium limitation is a key issue, motivating the use of reactive distillation (RD) to achieve high conversion and selectivity by shifting the chemical equilibrium boundaries, reducing byproduct, and overcoming azeotropic limitations. In addition, the $\mathrm{RD}$ process is motivated by benefits such as a reduction in the capital and operational costs due to combining the reaction and separation in a single unit. ${ }^{5,6}$ The $\mathrm{RD}$ process was first applied to the production of EtAc in $1932 .^{7}$ Since the production of methyl acetate via a commercial $\mathrm{RD}$ process by Eastman Chemical Co. in the $1980 \mathrm{~s},{ }^{8}$ it has become a new focus in both industry and academia. ${ }^{6,9,10}$

Pervaporation (PV) has been considered to be an effective technique to separate azeotropic mixtures and close-boilingpoint mixtures because it is not limited by the volatility of the components. ${ }^{1-13}$ As a low energy consumption, high selectivity, compact and modular design, and environmentally friendly process, PV has attracted intensive attention recently. ${ }^{14-17}$ However, PV is seldom used as a single process for the separation of species with high concentrations due to its relatively high capital cost and low capacity. Therefore, hybrid processes, coupling PV with other traditional separation technologies, e.g., a distillation process, are commonly used due to rising synergy effects and overcoming the disadvantages of each other. ${ }^{17-21}$ Lipnizki et al. ${ }^{17}$ made a detailed review of PV-based hybrid processes. Buchaly et al. ${ }^{18}$ described the modeling, simulation, and process analysis of hybrid separation processes combining $\mathrm{RD}$ with membrane separation for $n$ propyl propionate. Wang et al. ${ }^{19}$ proposed a new method for analyzing the $\mathrm{RD}-\mathrm{PV}$ process for ethyl tert-butyl ether from the viewpoint of nonequilibrium thermodynamics and the phenomenological theory. Aiouache and Goto $^{20}$ placed a tubular $\mathrm{NaA}$ zeolite membrane in an $\mathrm{RD}$ column for the continuous removal of generated water. The total output of tert-amyl ethyl ether was $10 \%$ higher than that without water removal. Huang et al. ${ }^{21}$ introduced an innovative separation process, which combines distillation, mechanical vapor compression, and vapor permeation, to improve process energy efficiency greatly.

For the production of EtAc by the $\mathrm{RD}$ process, the separation of products is difficult because of this fourcomponent system in the formation of several heterogeneous and homogeneous azeotropes. Most of the researchers focused on the effective separation of the distillate. ${ }^{22-25}$ In our previous work, a polyvinyl alcohol (PVA)/ceramic composite membrane was applied for the PV dehydration of the EtAc/ $\mathrm{H}_{2} \mathrm{O}$ binary and $\mathrm{EtAc} / \mathrm{EtOH} / \mathrm{H}_{2} \mathrm{O}$ ternary systems. ${ }^{26-28}$ Since the water content in the stoichiometry composition is $17.0 \%$ while in the

Received: February 15, 2012

Revised: $\quad$ May 19, 2012

Accepted: May 22, 2012

Published: May 22, 2012 
azeotrope compostion it is $8.7 \%$, the distillate contains less water in comparison to the water produced by chemical reaction. Accordingly, most of the water will coexist with the unreacted HAc in the reboiler, which significantly increases the energy consumption of the reboiler. The removal of water from HAc is therefore necessary, and the recycle of a large amount of unreacted HAc can be realized simultaneously. However, the difference in the volatilities of water and HAc is so small, especially at high HAc concentrations, that the energy-intensive azeotropic distillation or extractive distillation is always used to separate water from HAc.

In this work a new RD-PV coupled process was proposed for the EtAc production, in which the RD process was used for esterification and the PV process was simultaneously applied to remove the water from the reboiler and recycle the HAc into the feed. The water removal is beneficial for the esterification reaction, and moreover, the large amount of unreacted HAc in the reboiler can be reused. Therefore, this coupled process is not a simple integration of $\mathrm{RD}$ and $\mathrm{PV}$, but the PV process could have feedback to the $\mathrm{RD}$ process. To the best of our knowledge, although many processes are proposed for EtAc, ${ }^{7,29-34}$ this coupled process has not been reported to date. The synthesis of EtAc in an RD column was investigated via experiments and simulation using the Aspen Plus program. Meanwhile, we adopted the PVA/ceramic composite membrane for PV of model bottom solutions ( $\mathrm{HAc} / \mathrm{H}_{2} \mathrm{O}$ and $\mathrm{HAc} /$ EtAc/EtOH $/ \mathrm{H}_{2} \mathrm{O}$ mixtures). Subsequently, the RD-PV coupled process was established and the effects of coupled temperature and $\mathrm{HAc} / \mathrm{EtOH}$ molar ratio on the reaction conversion and EtAc in the distillate were systematically studied.

\section{EXPERIMENTAL SECTION}

2.1. Materials. Polyvinyl alcohol (PVA) was purchased from Shanghai RichJoint Chemical Reagents Co., Ltd., China. $\mathrm{HAc}$, EtOH, maleic anhydride, and sulfuric acid of analytical reagent grade were obtained from Sinopharm Chemical Reagent Co., Ltd., China. The preparation of the PVA/ceramic composite membrane followed the method reported in our previous work. $^{26}$

2.2. RD Experiment Setup, Packing, and Operation. Figure 1a shows the experimental apparatus. The pilot plant scale experiments were carried out in a glass column with an inner diameter of $30 \mathrm{~mm}$ and total height of $1.5 \mathrm{~m}$ at atmospheric pressure. The $\mathrm{RD}$ column consists of a $0.6 \mathrm{~m}$ long reactive section packed with homemade catalyst bales such as the catalyst licensed by CR\&L containing $0.1 \mathrm{~mm}$ diameter Purolite CT275 (a strong macroporous cation exchange resin) with a packing density of approximately $185 \mathrm{~kg} / \mathrm{m}^{3}$. The ion exchange capacity of CT275 is $5.2 \mathrm{H}^{+}$equiv $/ \mathrm{kg}$, and the maximum temperature limit is $145{ }^{\circ} \mathrm{C}$. The stripping section is $0.3 \mathrm{~m}$ and the rectifying section is $0.6 \mathrm{~m}$, and are packed with a Dixon ring ( $3 \mathrm{~mm}$ i.d.).

The column is equipped with an electronic reflux splitter to control the reflux ratio, a total condenser, and a reboiler with a four-neck round-bottom flask of a low liquid holdup (approximately $1 \mathrm{~L}$ ). The liquid in the reboiler was heated by a heating jacket. The value of the reboiler heat duty was calculated from the electric power to the mantle heater. The column and the reboiler were insulated by mineral wool to ensure adiabatic operation.

A sample of $200 \mathrm{~g}$ of EtOH was placed inside the bottom flask and heated to $100{ }^{\circ} \mathrm{C}$. When the distillate appeared at the

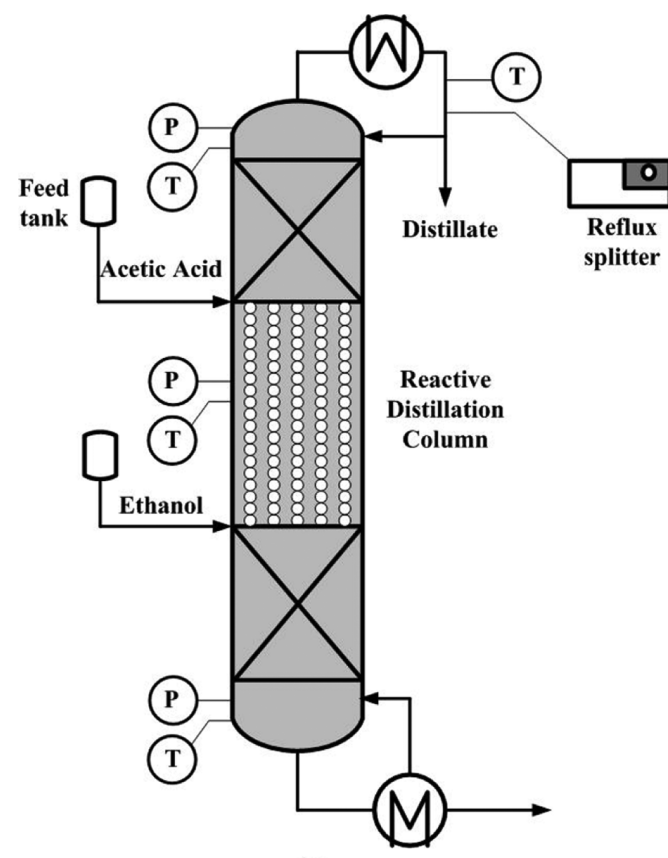

(a)

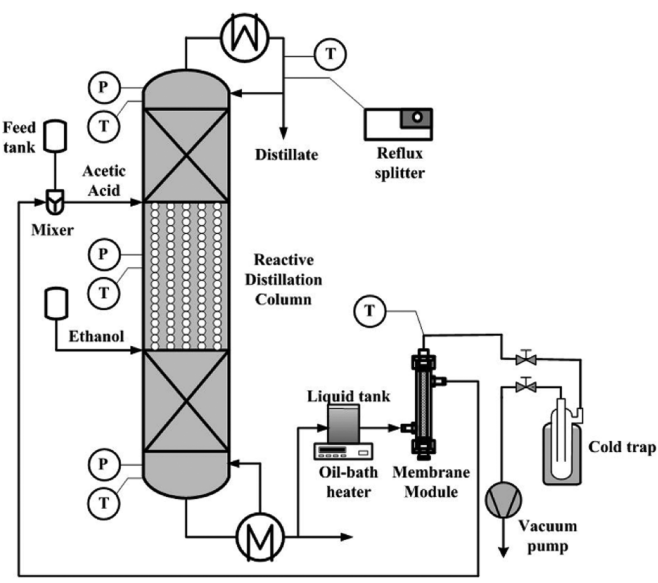

Figure 1. Experiment setup for (a) $\mathrm{RD}$ column and (b) $\mathrm{RD}-\mathrm{PV}$ coupled process.

top, the column was operated under total reflux until the temperature was maintained almost constant. Then HAc and EtOH were fed simultaneously by two pumps to the distillation column at the desired flow rates. The HAc feed port is located between the rectifying and reactive sections, and the $\mathrm{EtOH}$ feed port is located between the reactive and stripping sections. The excess liquid in the reboiler was withdrawn intermittently by another peristaltic pump to maintain the constant liquid level. The reflux splitter was adjusted to the desired values. Subsequently, the continuous operation was started and the experiment was conducted until steady state was achieved (usually $2.5 \mathrm{~h}$ ). The distillate, bottom withdrawal liquids, and permeate were periodically collected and analyzed. The pressure drop along the column is $540 \mathrm{~Pa} / \mathrm{m}$. The mass balance in the steady-state operation is about $98 \%$ closure.

2.3. PV and RD-PV Coupled Process. The PV performance of the membrane was conducted on a homemade PV apparatus, ${ }^{26}$ and the $\mathrm{RD}-\mathrm{PV}$ coupled process is shown in Figure $1 \mathrm{~b}$. The tubular PVA/ceramic composite membrane was 
sealed in a so-called "pencil module", ${ }^{35}$ with an effective membrane area of $110 \mathrm{~cm}^{2}$. The PV feed was heated by the oilbath heater and circulated by a liquid pump between the membrane module and the liquid tank with a circulation flow of $23.4 \mathrm{~L} / \mathrm{h}$. The vapor permeated through the membrane was collected in a liquid nitrogen trap, and the permeate pressure was kept at 300-400 Pa during collections. After the RD column reached a steady state, the membrane was coupled with the reboiler and the RD-PV coupled process was started. The $\mathrm{RD}$ process was kept going while the generated water was removed from the reboiler simultaneously via the pervaporation process.

The PV performance of a membrane is usually expressed in terms of the permeation flux $J_{i}$ and separation factor $\alpha$.

$$
\begin{aligned}
& J_{i}=\frac{W_{i}}{A t} \\
& \alpha=\frac{y_{i} / y_{j}}{x_{i} / x_{j}}
\end{aligned}
$$

where $W_{i}$ is the weight of component $i$ in the permeate $(\mathrm{kg}), A$ is the effective area of the membrane $\left(\mathrm{m}^{2}\right)$, and $t$ is the permeation time interval for the PV $(\mathrm{h}) ; x_{i}, x_{j}$, and $y_{i} y_{j}$ represent the weight fractions of the components $i$ and $j$ in the permeate and feed, respectively.

On the basis of the solution-diffusion model, the transport equation for the PV process can be expressed as ${ }^{36}$

$$
Q_{i}=\frac{J_{i}}{\gamma_{i \mathrm{o}}^{\mathrm{L}} x_{i \mathrm{o}}^{\mathrm{L}} P_{i \mathrm{o}}^{\mathrm{sat}}-y_{i} P_{y}}
$$

where $J_{i}$ and $Q_{i}$ are the permeation flux and the permeance of component $i, \gamma_{i o}^{\mathrm{L}}$ is the activity coefficient of $i$ in the feed liquid, $x_{i \mathrm{o}}^{\mathrm{L}}$ and $y_{i}$ are the mole fractions of component $i$ in the feed side and in the permeate side, and $P_{i o}^{\text {sat }}$ and $P_{y}$ are the saturated vapor pressure of component $i$ and the total permeate pressure.

The selectivity of the membrane $\beta$ is defined as

$$
\beta=\frac{Q_{i}}{Q_{j}}
$$

where $Q_{i}$ and $Q_{j}$ are the permeances of components $i$ and $j$, respectively.

The apparent activation energy $\left(E_{\mathrm{p} i}\right)$ is calculated using the Arrhenius equation:

$$
J_{i}=K \exp \left(\frac{-E_{\mathrm{p} i}}{R T}\right)
$$

where $J_{i}$ is the flux of component $i, K$ is the permeation rate constant, $T$ is the feed absolute temperature, and $R$ is the molar gas constant.

2.4. Analysis. A gas chromatograph (GC-2014, SHIMAD$\mathrm{ZU}$, Japan) equipped with a thermal conductivity detector (TCD) was used to analyze the mixture of EtOH, HAc, EtAc, and water. The analysis process was carried out in a Porapak-Q column with helium as a carrier gas at a flow rate of $25 \mathrm{~mL} /$ min. The oven temperature was varied from 120 to $180{ }^{\circ} \mathrm{C}$.

\section{RESULTS AND DISCUSSION}

In order to establish the $\mathrm{RD}-\mathrm{PV}$ coupled process, the main influencing factors of the individual $\mathrm{RD}$ and PV process were investigated respectively, because the performance of the $\mathrm{RD}-$
PV coupled process was to some extent determined by these two individual processes. For the $\mathrm{RD}$ process, three conventional factors are chosen: reflux ratio, $\mathrm{HAc} / \mathrm{EtOH}$ molar ratio, and total feed rate; For the PV process, the operating temperature and feed concentration are usually the main factors.

3.1. RD Experiment and Simulation. 3.1.1. Effect of Reflux Ratio. The reflux ratio is a very important parameter in an $\mathrm{RD}$ process. The influences of the reflux ratio on the EtAc purity in the distillate, the water concentration in the reboiler, and the $\mathrm{EtOH}$ conversion were investigated. The molar ratio of $\mathrm{HAc}$ to EtOH was set at 1.1, the flow rate of $\mathrm{EtOH}$ was $42 \mathrm{~g} / \mathrm{h}$, and the mass ratio of distillate to feed $(\mathrm{D} / \mathrm{F})$ was set at 0.71 .

As shown in Figure 2, both the EtAc purity in the distillate and the water in the bottom are highest at the reflux ratio of 3 .
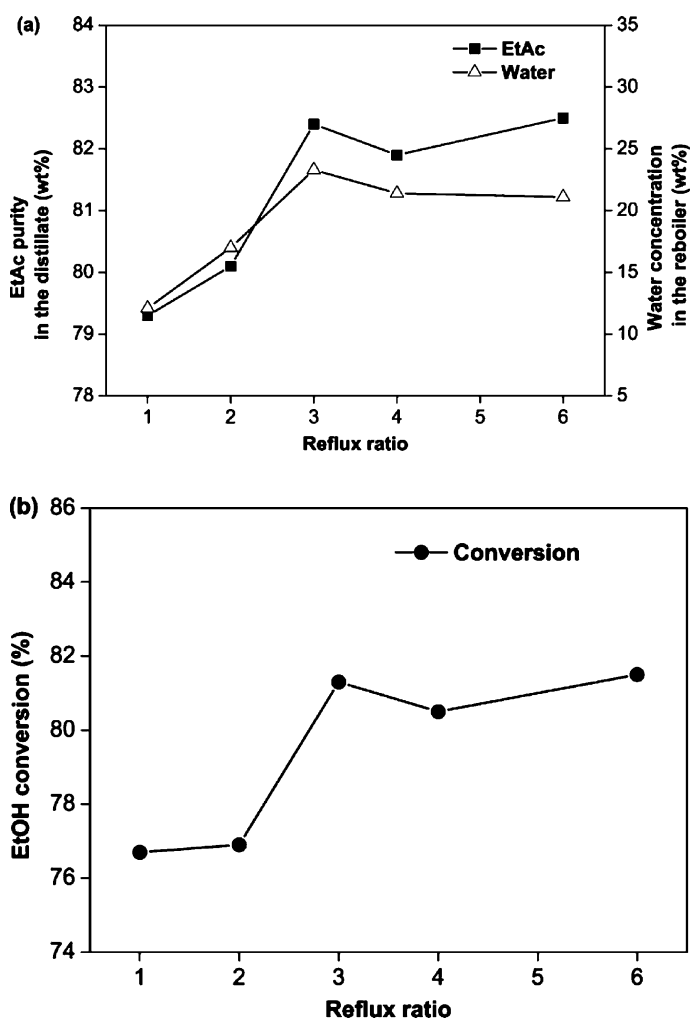

Figure 2. Effect of reflux ratio on (a) EtAc purity in the distillate and water concentration in the reboiler and (b) $\mathrm{EtOH}$ conversion ( $\mathrm{HAc} /$ $\mathrm{EtOH}$ molar ratio $=1.1, \mathrm{EtOH}$ feed rate $=42 \mathrm{~g} / \mathrm{h}$ and $\mathrm{D} / \mathrm{F}=0.71)$.

The conversion of the EtOH is 81.3 wt \%. The increase of the reflux ratio from 1 to 3 overcomes the chemical equilibrium limitation, enhances the conversion beyond the chemical equilibrium conversion, and improves the EtAc purity in the distillate and $\mathrm{EtOH}$ conversion. When the reflux ratio increased from 3 to 6, the high reflux ratio led to high EtAc concentration in the reactive zone, reducing the residence time and suppressing the shift of the positive reaction; thus the EtAc concentration in the distillate and the $\mathrm{EtOH}$ conversion changed slightly. Considering the energy consumption, the reflux ratio of 3 is appropriate.

3.1.2. Effect of HAC/EtOH Molar Ratio. It is well-known that increasing one of the reactants in an equilibrium limited reaction can lead to increasing the conversion of the other reactants. For EtAc production, excessive HAc is usually used. The effect of the HAc/EtOH molar ratio on EtAc purity in the 
distillate and water concentration in the reboiler was studied with the EtOH feed rate and reflux ratio of $42 \mathrm{~g} / \mathrm{h}$ and 3, respectively. The results are shown in Figure 3.
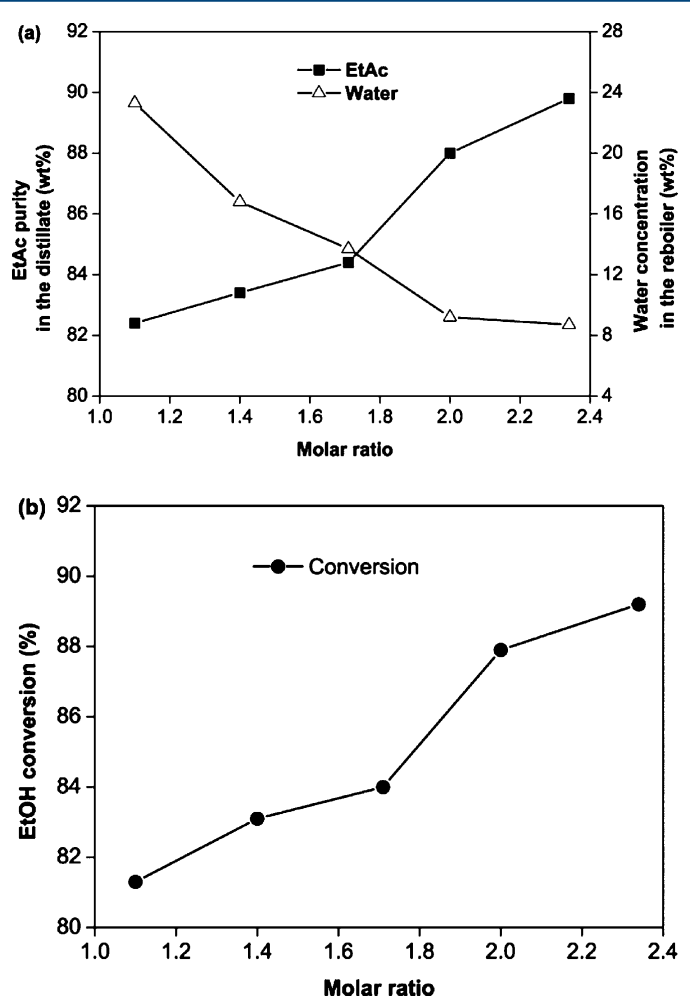

Figure 3. Effect of molar ratio of $\mathrm{HAc}$ to $\mathrm{EtOH}$ on (a) EtAc purity in the distillate and water concentration in the reboiler and (b) EtOH conversion $(\mathrm{EtOH}$ feed rate $=42 \mathrm{~g} / \mathrm{h}$ and reflux ratio $=3$ ).

EtAc purity and EtOH conversion increase with increasing $\mathrm{HAc} / \mathrm{EtOH}$ molar ratio. EtAc purity in the distillate is $84.4 \mathrm{wt}$ $\%$ at the ratio of 1.7. Because of the low $\mathrm{EtOH}$ concentration, the distillate can be separated into organic phase and water phase spontaneously. It is noted that the EtAc purity increases rapidly as the $\mathrm{HAc} / \mathrm{EtOH}$ molar ratio increases from 1.7 to 2.0, whereas the water concentration has not been changed dramatically. At the $\mathrm{HAc} / \mathrm{EtOH}$ molar ratio of 2.0, the water concentration is about $10 \mathrm{wt} \%$ in the reboiler, which is half that at the molar ratio of 1.1. Considering the economy, the appropriate molar ratio is 2.0.

3.1.3. Effect of Total Feed Rate. The total feed rate has a significant influence on the residence time of the reactants in the reactive zone. Experiments were carried out to study the effect of total feed rate on the performance of $\mathrm{RD}$ with the reflux ratio and $\mathrm{HAc} / \mathrm{EtOH}$ molar ratio of 3 and 2, respectively. As shown in Figure 4, when the feed rate increases, the residence time of the reactants decreases, causing the drop in both EtAc purity and EtOH conversion. Considering the column capacity and EtOH conversion, a total feed rate of 152 $\mathrm{g} / \mathrm{h}$ is appropriate.

Furthermore, the Aspen Plus program was applied to check the optimum results of the $\mathrm{RD}$ experiment (see Supporting Information). The simulation was conducted under optimized $\mathrm{RD}$ parameters. The results and the corresponding experimental data are listed in Table S1 in the Supporting Information. It can be found that the theoretical results agree
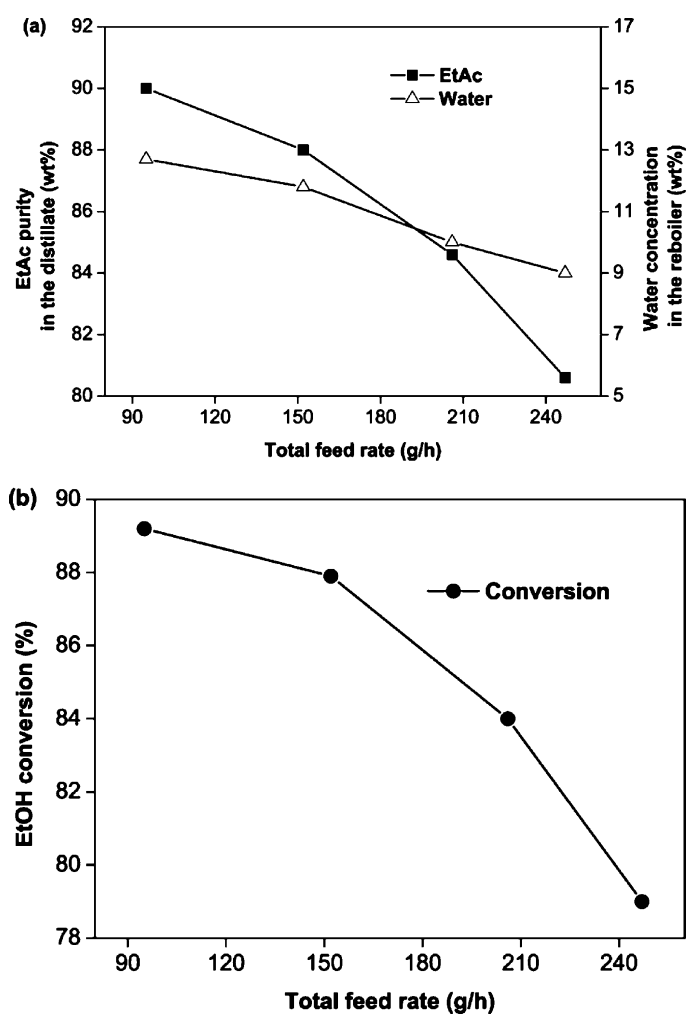

Figure 4. Effect of total feed rate on (a) EtAc purity in the distillate and water concentration in the reboiler and (b) EtOH conversion $(\mathrm{HAc} / \mathrm{EtOH}$ molar ratio $=2$ and reflux ratio $=3)$.

well with the experimental data for both distillate and bottom concentrations.

3.2. PV Dehydration of Bottom Solutions. 3.2.1. PV Dehydration of $\mathrm{HAC} / \mathrm{H}_{2} \mathrm{O}$ Solution. The PV dehydration of $\mathrm{RD}$ bottom solutions was investigated first based on the model $\mathrm{HAc} / \mathrm{H}_{2} \mathrm{O}$ mixtures. The effects of operating temperature and feedwater content on the PV performance were investigated. It should be noted that the temperature of the $\mathrm{RD}$ reboiler was $100{ }^{\circ} \mathrm{C}$ and the maximum water content was less than $30 \mathrm{wt} \%$. See Figure 5.

When the operation temperature increased, the partial pressure of the water and HAc in the feed side increased while the vapor pressure at the permeate side was not affected. As a consequence, the driving force for mass transfer across the membrane increased with the feed temperature. In addition, the diffusion of the water and HAc molecules was enhanced due to the high temperature, which favored the mass transfer of the process. Furthermore, high temperature would increase the mobility of the polymer chains and the expansion of the free volume. All these factors favored the increase of the water flux and the HAc flux, and the increase of the HAc flux was higher than that of water. Therefore, increasing temperature led to an increase in flux and an decrease in separation factor.

As water in the feed increases, the permeation flux of the membrane increases, whereas the separation factor significantly decreases (Figure 5). Increasing the water content in the feed facilitates the water sorption into the PVA membrane; thus the hydrophilic PVA layer is more swollen. This makes the diffusion of both water and HAc molecules through the membrane easy. As a result, the total permeation flux increases and the separation factor decreases. 

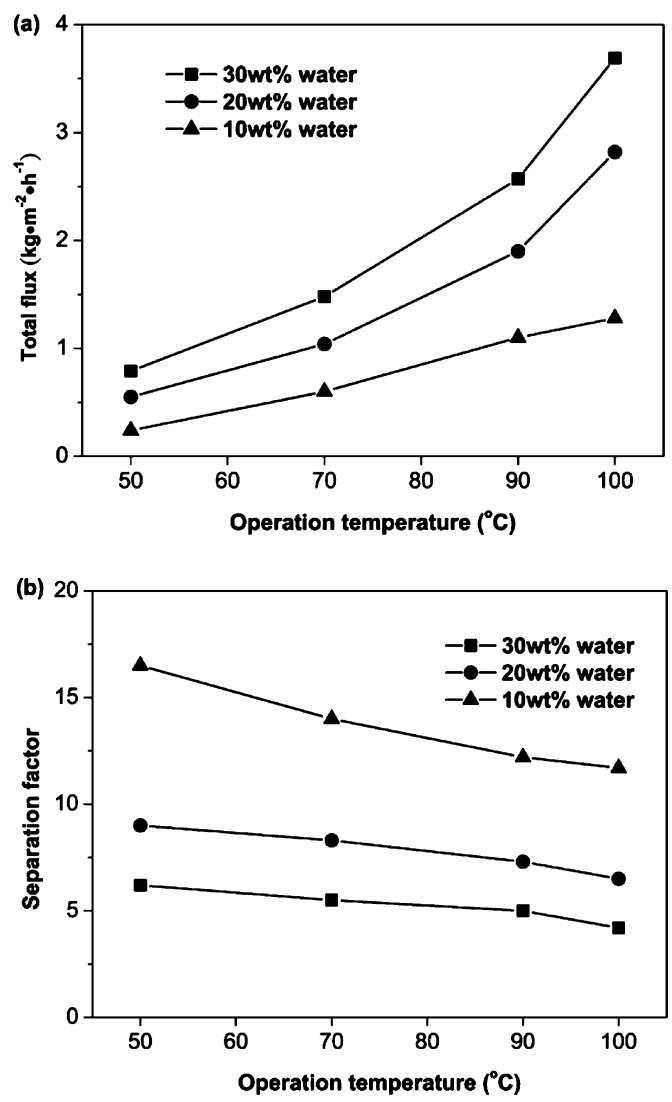

Figure 5. Effect of operation temperature and feedwater content on (a) total flux and (b) separation factor.

Comparison of the PV performance of this work with other reports for $\mathrm{HAc} / \mathrm{H}_{2} \mathrm{O}$ mixtures is summarized in Table 1 . Considering the different operating conditions of the PV experiments, the permeance and selectivity that reflect the intrinsic properties of the membranes were also calculated by eqs 3 and 4 . It can be seen that the PVA/ceramic composite membrane exhibits good performance for the dehydration of $\mathrm{HAc} / \mathrm{H}_{2} \mathrm{O}$ mixtures, and might be a promising PV membrane for the RD-PV coupled process.

3.2.2. Long-Term Stability of the PVA/Ceramic Composite Membrane. The lifetime or durability of the membrane is one of the important factors that should be considered for practical application. The long-term stability of PVA/ceramic composite membrane was investigated in the $\mathrm{HAc} / \mathrm{H}_{2} \mathrm{O}$ system at $70{ }^{\circ} \mathrm{C}$, as shown in Figure 6. During the $100 \mathrm{~h}$ testing period, the permeation flux and separation factor are steadily kept at around $0.6 \mathrm{~kg} \cdot \mathrm{m}^{-2} \cdot \mathrm{h}^{-1}$ and 14 , respectively. Because of the sufficient mechanical, chemical, and thermal stabilities of the PVA/ceramic composite membrane, it can be adopted for the

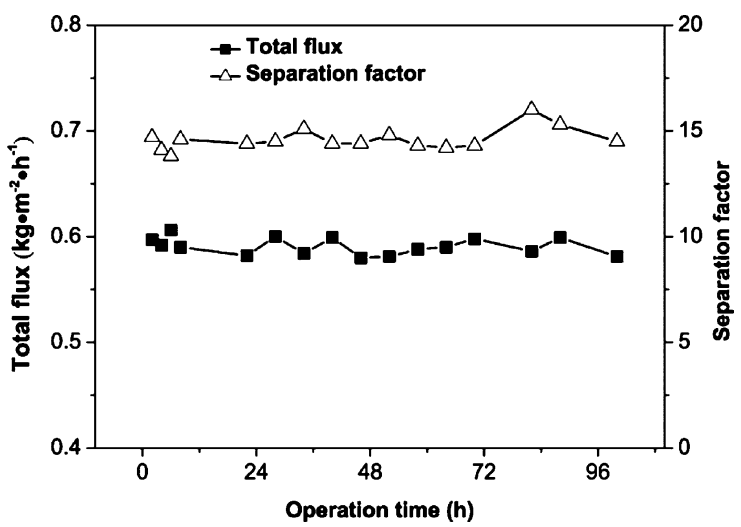

Figure 6. Effect of operation time on the PV performance of PVA/ ceramic composite membrane in $\mathrm{HAc} /$ water mixtures $(10 \mathrm{wt} \%$ water at $\left.70^{\circ} \mathrm{C}\right)$.

dehydration of $\mathrm{HAc} / \mathrm{H}_{2} \mathrm{O}$ solution at relatively high temperature. The three-dimensional swelling of the organic layer is restricted by the ceramic supports, which is beneficial to the long-term stability of the PVA/ceramic composite membrane. ${ }^{41}$

3.2.3. PV Dehydration for $\mathrm{HAc} / \mathrm{EtAc} / \mathrm{EtOH} / \mathrm{H}_{2} \mathrm{O}$ Quaternary Solutions. The PVA/ceramic composite membrane shows good dehydration performance for the $\mathrm{HAc} / \mathrm{H}_{2} \mathrm{O}$ binary solution. In most of the $\mathrm{RD}$ process, however, the bottom products are $\mathrm{HAc} / \mathrm{H}_{2} \mathrm{O} / \mathrm{EtAc} / \mathrm{EtOH}$ quaternary solutions. Therefore, the PV dehydration performance of the PVA/ ceramic composite membrane in a typical $\mathrm{HAc} / \mathrm{H}_{2} \mathrm{O} / \mathrm{EtAc} /$ $\mathrm{EtOH}(80 / 12 / 6 / 2$ wt \%) quaternary solution was investigated at different temperatures, as shown in Figure 7. As temperature increases from 50 to $100{ }^{\circ} \mathrm{C}$, the total flux increases from 0.35 to $1.27 \mathrm{~kg} \cdot \mathrm{m}^{-2} \cdot \mathrm{h}^{-1}$ while the water concentration in the permeate decreases from 67.7 to $63.3 \mathrm{wt} \%$. The permeation fluxes and concentrations of EtOH and EtAc are very low. Furthermore, the Arrhenius plots of the PV performance of the PVA/ceramic composite membrane are shown in Figure 8. Good linearity relationships between the permeation fluxes and the reciprocal of the temperature $(1 / T)$ can be observed. The activation energy values for each component through the composite membrane were calculated from the slope. The activation energy values for water, $\mathrm{HAc}, \mathrm{EtOH}$, and EtAc are 25.1, 29.4, 28.7, and $16.6 \mathrm{~kJ} \cdot \mathrm{mol}^{-1}$, respectively.

3.3. RD-PV Coupled Process. As discussed above, the operating temperature and water concentration have significant effects on the permeate flux and composition of the PV process. Thus, to investigate the effect of the PV process on the RD-PV coupled process, two critical factors were chosen: the PV operating temperature and the $\mathrm{HAc} / \mathrm{EtOH}$ molar ratio of $\mathrm{RD}$ that determines the water concentration of the bottom solution. The experiments were carried out at a constant permeate

Table 1. Comparison of PV Performance of the Composite Membrane with Other Published Works

\begin{tabular}{|c|c|c|c|c|c|c|c|}
\hline membrane $^{a}$ & water content (wt \%) & temp $\left({ }^{\circ} \mathrm{C}\right)$ & total flux $\left(\mathrm{g} \cdot \mathrm{m}^{-2} \cdot \mathrm{h}^{-1}\right)$ & water permeance $\left(\mathrm{g} \cdot \mathrm{m}^{-2} \cdot \mathrm{h}^{-1} \cdot \mathrm{kPa}^{-1}\right)$ & separation factor & selectivity & ref \\
\hline PVA-TEOS & 10 & 50 & 185 & 25.71 & 14.0 & 1.86 & 37 \\
\hline PVA & 10 & 45 & 37.1 & 6.34 & 11.6 & 1.55 & 38 \\
\hline NaAlg & 10 & 70 & 269 & 10.99 & 9.0 & 1.08 & 39 \\
\hline $\mathrm{ZSM}-5 / \alpha-\mathrm{Al}_{2} \mathrm{O}_{3}$ & 50 & 70 & 301 & 11.23 & 14.0 & 4.47 & 40 \\
\hline PVA/ceramic & 10 & 50 & 240 & 31.29 & 16.5 & 2.09 & this work \\
\hline PVA/ceramic & 10 & 70 & 600 & 28.77 & 14.0 & 1.68 & this work \\
\hline
\end{tabular}

${ }^{a}$ TEOS, tetraethoxysilane; NaAlg, sodium alginate. 

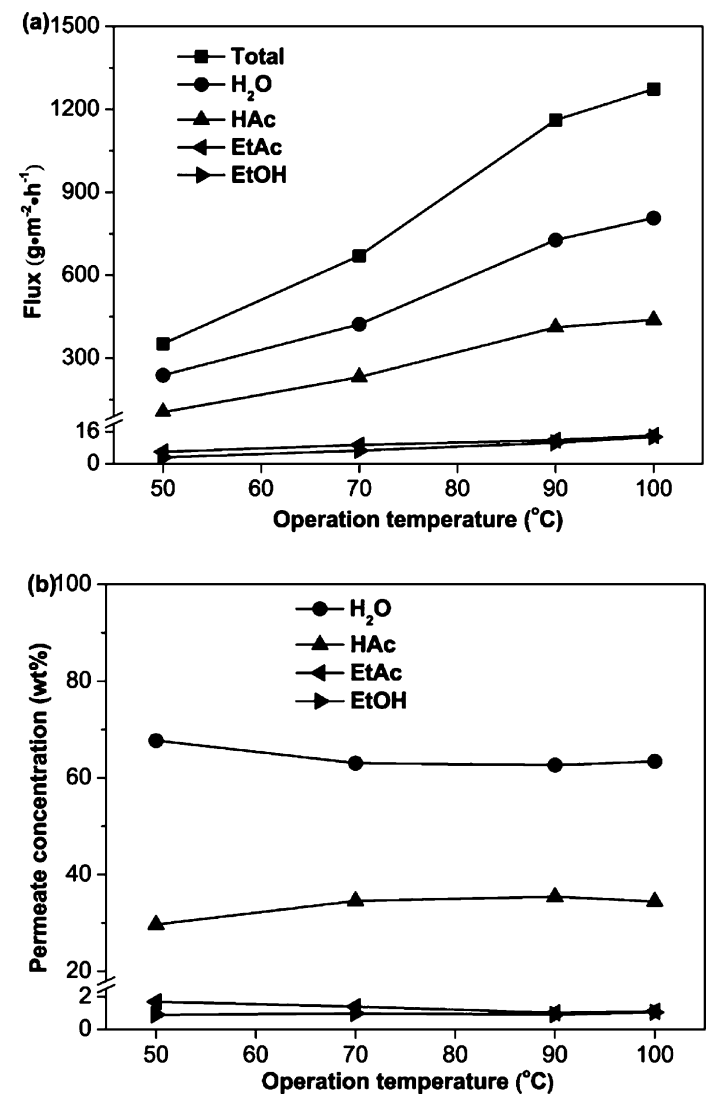

Figure 7. Effect of operation temperature on (a) Flux and (b) permeate concentration of $\mathrm{PVA} /$ ceramic composite membrane in $\mathrm{HAc} / \mathrm{H}_{2} \mathrm{O} / \mathrm{EtAc} / \mathrm{EtOH}$ quaternary solutions (80/12/6/2 wt \%).

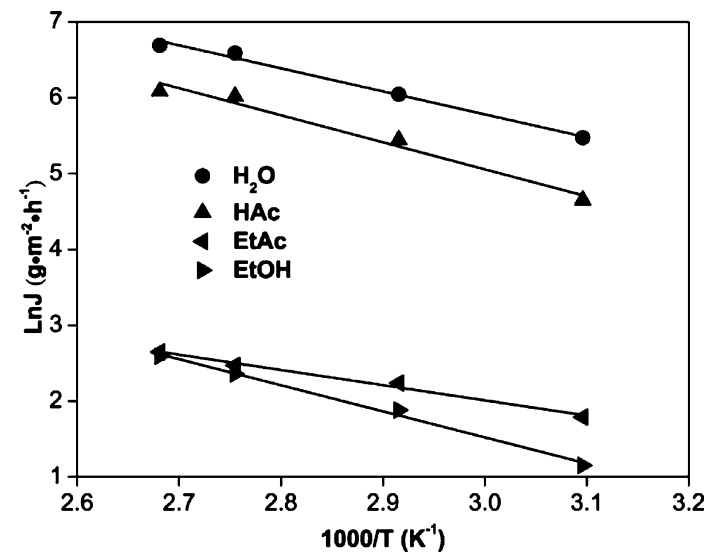

Figure 8. Arrhenius plots between the permeation flux of the membrane and the reciprocal feed temperature for PV.

pressure of $350 \mathrm{~Pa}$ and a retentate reflux to HAc feed of 30 $\mathrm{mL} / \mathrm{h}$.

3.3.1. Effect of PV Operating Temperature. At the optimal conditions of the $\mathrm{RD}$ process (reflux ratio $=3, \mathrm{HAc} / \mathrm{EtOH}$ molar ratio $=2$, total feed rate $=152 \mathrm{~g} / \mathrm{h}$ ), the effect of PV operating temperature on the performance of the $\mathrm{RD}-\mathrm{PV}$ coupled process was investigated. As shown in Figure 9, the higher PV operating temperature is benefit for the RD-PV coupled process. The EtAc purity in the distillate and the EtOH conversion reach 91.0 wt $\%$ and $90.2 \%$, respectively, with the PV process operated at $100{ }^{\circ} \mathrm{C}$.
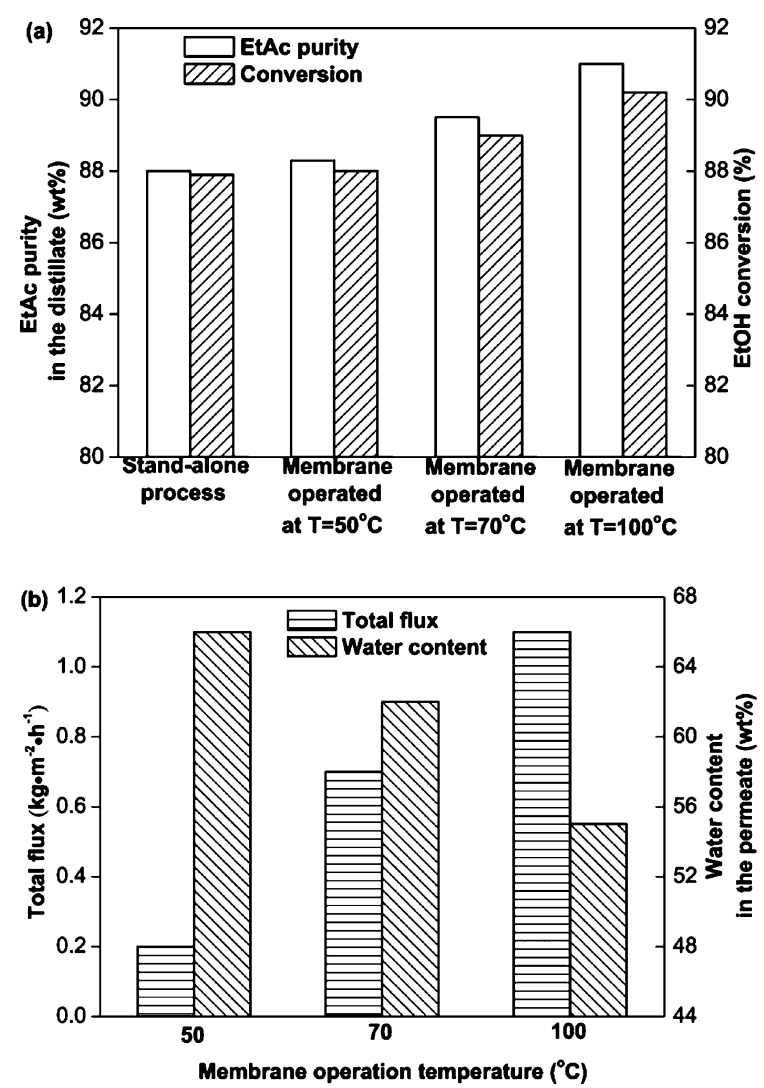

Figure 9. Effect of coupled temperatures on (a) EtAc purity in the distillate and EtOH conversion and (b) total flux and water content in the permeate.

The "coupling effect" of the RD-PV coupled process can be stated as follows: since water was removed from the bottom, the esterification was shifted toward the formation of more EtAc. In addition, due to the increase in the permeation flux and HAc content in the retentate, the actual HAc/EtOH molar ratio increased in the $\mathrm{RD}$ column, thus improving both the EtAc purity and the EtOH conversion simultaneously. Furthermore, the permeation fluxes of EtOH and EtAc are very low (as displayed in Figure 7); thus the unreacted EtOH (ca. $4 \mathrm{wt} \%$ ) in the reboiler was reflowed to the reaction zone to react with $\mathrm{HAc}$, improving the EtAc purity and EtOH conversion as well. Meanwhile, the EtAc in the reboiler was also reflowed to the reaction zone, which is beneficial for higher EtAc purity in the distillate.

3.3.2. Effect of $\mathrm{HAc} / \mathrm{EtOH}$ Molar Ratio. In the $\mathrm{RD}$ process, as the $\mathrm{HAc} / \mathrm{EtOH}$ molar ratio increases, a large amount HAc coexists with the water at the column bottom, which leads to the increase of the separation burden of the reboiler compounds. Therefore, we attempted to study the RD-PV coupled process at low $\mathrm{HAc} / \mathrm{EtOH}$ molar ratios, in order to relieve the burden of reboiler. The performance of the $\mathrm{RD}-\mathrm{PV}$ coupled process at various $\mathrm{HAc} / \mathrm{EtOH}$ molar ratios at $70{ }^{\circ} \mathrm{C}$ is shown in Figure 10. It was found that by coupling with the PV process the performance of the $\mathrm{RD}$ process could be improved under all $\mathrm{HAc} / \mathrm{EtOH}$ molar ratios. Moreover, the performance improvement of the $\mathrm{RD}$ process via coupled with $\mathrm{PV}$ at a low $\mathrm{HAc} / \mathrm{EtOH}$ molar ratio was much higher than that of the RDPV coupled process operating at a high $\mathrm{HAc} / \mathrm{EtOH}$ molar ratio. The reason is that, at the molar ratio of 1.1 , the high water concentration in the reboiler leads to a high permeation flux of 

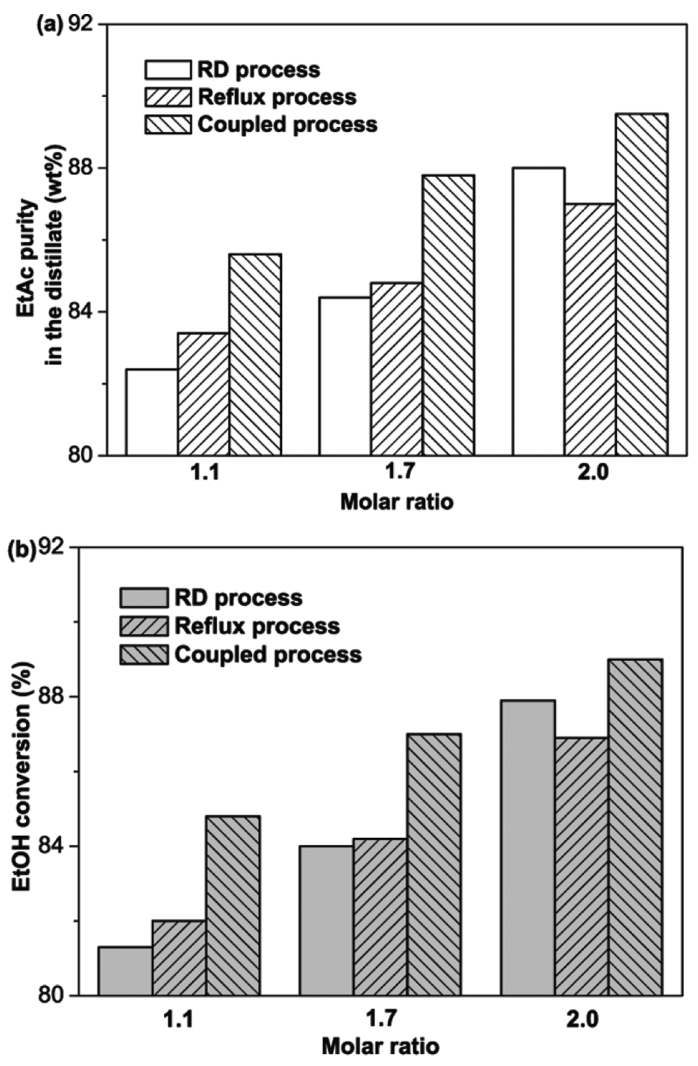

Figure 10. Effect of $\mathrm{HAc} / \mathrm{EtOH}$ molar ratio on (a) EtAc purity in the distillate and (b) EtOH conversion of the stand-alone RD, RD only with recycle stream, and $\mathrm{RD}-\mathrm{PV}$ coupled process.

the PV process (as displayed in Figure 5a), resulting a significant "coupling effect" as discussed in section 3.3.1.

We also found that, when coupled with PV, the EtAc purity and $\mathrm{EtOH}$ conversion at the molar ratio of 1.1 was higher than those of the stand-alone $\mathrm{RD}$ at the molar ratio of 1.7; the performance of the $\mathrm{RD}-\mathrm{PV}$ coupled process at the molar ratio of 1.7 was nearly up to that of the stand-alone $\mathrm{RD}$ at the molar ratio of 2.0, as well. This result suggests that the coupling of the $\mathrm{PV}$ process could realize the $\mathrm{RD}$ process operating at a low $\mathrm{HAc} / \mathrm{EtOH}$ molar ratio, meanwhile keeping a high product quality and reaction conversion. It favors the subsequent treatment of the bottom solution. Furthermore, the distillate can be separated into the organic phase and water phase due to the low EtOH concentration in this case, thus making the subsequent separation much easier.

To further investigate the effect of the PV process in this coupled process, we also carried out the RD process only with a recycle stream into the HAc feed without the water removal by the PV process. The results comparison is also shown in Figure 10. The recycle of the reboiler has two effects on the performance of the reaction. On one hand, the improved molar ratio of $\mathrm{HAc}$ to $\mathrm{EtOH}$ will facilitate the shift of positive reaction; on the other hand, the water in the recycle will also suppress the shift of positive reaction. When the molar ratio was 1.1 and 1.7, the domination of former effect resulted in the increase of the conversion and EtAc purity in the distillate. As the molar ratio increased to 2.0, the latter effect became dominant, leading to the drop of both the conversion and EtAc purity. Nevertheless, in the RD-PV coupled process, due to the water removal from the reboiler by the PV membrane, both the conversion and the EtAc purity were higher than those with the
$\mathrm{RD}$ process only with a recycle stream. Therefore, it was further proved that the improvement of $\mathrm{EtOH}$ conversion and EtAc purity in the distillate were due to the water removal from the reboiler and the HAc recycle to feed by the coupling of the PV process. Especially, the pervaporation removal of water would play a dominant factor under high feed $\mathrm{HAc} / \mathrm{EtOH}$ molar ratios.

\section{CONCLUSIONS}

A new RD-PV coupled process with PV selectively removing water from the reboiler and recycling HAc into the feed for EtAc production is presented. An optimal $\mathrm{RD}$ operating condition was obtained via experiments and Aspen Plus simulation. The PVA/ceramic composite membrane showed good performance and stability with a total flux of 600 $\mathrm{g} \cdot \mathrm{m}^{-2} \cdot \mathrm{h}^{-1}$ and separation factor of 14 in $90 \mathrm{wt} \% \mathrm{HAc} /$ water solution at $70{ }^{\circ} \mathrm{C}$. As a result, the removal of water and recycle of bottom withdrawal by PV coupling significantly improved both the product purity and the reaction conversion of the $\mathrm{RD}$ process, in which the ethyl acetate purity and ethanol conversion simultaneously increased from 82.4 to $85.6 \mathrm{wt} \%$ and from 81.3 to $84.8 \%$, respectively, at low the $\mathrm{HAc} / \mathrm{EtOH}$ molar ratio of 1.1. Our work demonstrated that this novel RDPV coupled process based on the PVA/ceramic composite membrane could be a promising method to produce ethyl acetate. Further work could focus on the development of a higher-selective membrane for the $\mathrm{HAc} / \mathrm{H}_{2} \mathrm{O}$ system, which will solve the problem of high $\mathrm{HAc}$ contents in the PV permeate.

\section{ASSOCIATED CONTENT}

S Supporting Information

Application of Aspen Plus program to check the optimum results of the $\mathrm{RD}$ experiment. This material is available free of charge via the Internet at http://pubs.acs.org.

\section{AUTHOR INFORMATION}

\section{Corresponding Author}

*Tel.: +86-25-83172266. Fax: +86-25-83172292. E-mail: wqjin@njut.edu.cn.

\section{Notes}

The authors declare no competing financial interest.

\section{ACKNOWLEDGMENTS}

This work was supported by the National Basic Research Program of China (No. 2009CB623406) and the National Natural Science Foundation of China (Nos. 20990222 and 21006047).

\section{REFERENCES}

(1) Dean, J. A. Lange's Handbook of Chemistry; 15th ed.; McGrawHill: New York, 1999.

(2) Levin, S. J.; Johnston, C. G.; Boyle, A. J. Spectrophotometric determination of several bile acids as conjugates, extraction with ethyl acetate. Anal. Chem. 1961, 33, 1407.

(3) Dutia, P. Ethyl acetate: a techno-commercial profile. Chem. Wkly. Bombay 2004, 49, 179.

(4) McMurry, J. Organic Chemistry, 5th ed.; Brooks/Cole: Pacific Grove, CA, USA, 2000.

(5) Doherty, M. F.; Buzad, G. Reactive distillation by design. Chem. Eng. Res. Des. 1992, 70, 448.

(6) Taylor, R.; Krishna, R. Modeling Reactive Distillation. Chem. Eng. Sci. 2000, 55, 5183. 
(7) Keyes, D. B. Esterification processes and equipment. Ind. Eng. Chem. 1932, 24, 1096.

(8) Agreda, V. H.; Partin, P. H.; Heise, W. H. High purity methyl acetate via reactive distillation. Chem. Eng. Prog. 1990, 86, 40.

(9) Hiwale, R. S.; Mahajan, Y. S.; Bhate, N. V.; Mahajani, S. M. Industrial Application of Reactive Distillation: Recent Trends. Int. J. Chem. React. Eng. 2004, 2, R1.

(10) Harmsen, G. J. Reactive distillation: The front-runner of industrial process intensification A full review of commercial applications, research, scale-up, design and operation. Chem. Eng. Process. 2007, 46, 774.

(11) Dutta, B. K.; Sridhar, S. K. Separation of azeotropic organic liquid mixtures by pervaporation. AIChE J. 1991, 37, 581.

(12) Baelen, D. V.; Bruggen, B. V.; Dungen, K. V.; Degreve, J.; Vandecasteele, C. Pervaporation of water-alcohol mixtures and acetic acid-water mixtures. Chem. Eng. Sci. 2005, 60, 1583.

(13) Khayet, M.; Cojocaru, C.; Zakrzewska-Trznadel, G. Studies on pervaporation separation of acetone, acetonitrile and ethanol from aqueous solutions. Sep. Purif. Technol. 2008, 63, 303.

(14) Feng, X.; Huang, R. Y. M. Liquid separation by membrane pervaporation: a review. Ind. Eng. Chem. Res. 1997, 36, 1048.

(15) Jonquieres, A.; Clement, R.; Lochon, P.; Neel, J.; Dresch, M.; Chretien, B. Industrial state-of-the-art of pervaporation and vapour permeation in the western countries. J. Membr. Sci. 2002, 206, 87.

(16) Smitha, B.; Suhanya, D.; Sridhar, S.; Ramakrishna, M. Separation of organic-organic mixtures by pervaporation_ a review. J. Membr. Sci. 2004, 241, 1.

(17) Lipnizki, F.; Field, R. W.; Ten, P. K. Pervaporation-based hybrid process: a review of process design, applications and economics. $J$. Membr. Sci. 1999, 153, 183.

(18) Buchaly, C.; Kreis, P.; Gorak, A. Hybrid separation processes_combination of reactive distillation with membrane separation. Chem. Eng. Process. 2007, 46, 790.

(19) Wang, H. J.; Yang, B. L.; Wu, J.; Zhao, G. S.; Tao, X. H. Multifields synergy in the process of reactive distillation coupled with membrane separation. Chem. Eng. Process. 2005, 44, 1207.

(20) Aiouache, F.; Goto, S. Reactive distillation-pervaporation hybrid column for tert-amyl alcohol etherification with ethanol. Chem. Eng. Sci. 2003, 58, 2465.

(21) Huang, Y.; Baker, R. W.; Leland, M. V. Low-Energy DistillationMembrane Separation Process. Ind. Eng. Chem. Res. 2010, 49, 3760.

(22) Berg, L.; Ratanapupech, P. Process for the separation of ethyl acetate from ethanol and water by extractive distillation. U.S. Patent 4,569,726, 1986.

(23) Colley, S. W.; Fawcett, C. R.; Sharif, M.; Tuck, M. W. M.; Watson, D. J.; Wood, M. A. U.S. Patent 7,553,397, 2009.

(24) Horan, K. A.; Murphy, C. D.; Warner, R. J.; Windhorst, K. A. Process improvement for continuous ethyl acetate production. U.S. Patent 6,768,021, 2004.

(25) Zhang, X. H.; Liu, Q. L.; Xiong, Y.; Zhu, A. M.; Chen, Y.; Zhang, Q. G. Pervaporation dehydration of ethyl acetate/ethanol/ water azeotrope using chitosan/poly(vinyl pyrrolidone) blend membranes. J. Membr. Sci. 2009, 327, 274.

(26) Zhu, Y. X.; Xia, S. S.; Liu, G. P.; Jin, W. Q. Preparation of ceramic-supported poly(vinylacohol)-chitosan composite membranes and their applications in dehydration of organic/water mixtures. $J$. Membr. Sci. 2010, 349, 341.

(27) Xia, S. S.; Dong, X. L.; Zhu, Y. X.; Wei, W.; Xiangli, F. J.; Jin, W. Q. Dehydration of ethyl acetate-water mixtures using PVA/ceramic composite pervaporation membrane. Sep. Purif. Technol. 2010, 77, 53.

(28) Xia, S. S.; Wei, W.; Liu, G. P.; Dong, X. L.; Jin, W. Q. Pervaporation properties of polyvinyl alcohol/ceramic composite membrane for separation of ethyl acetate/ethanol/water ternary mixtures. Korean J. Chem. Eng. 2012, 29, 228.

(29) Wu, K. C.; Lin, C. T. Catalytic processes for the preparation of acetic esters. U.S. Patent 5,998,658, 1999.

(30) Kolena, J.; Lederer, J.; Moravek, P.; Hanika, J.; Smejkal, Q.; Skala, D. Method of producing ethyl acetate and an equipment for carrying out this method. U.S. Patent 6,693,213, 2004.
(31) Kenig, E. Y.; Bader, H.; Gorak, A.; Bessling, B.; Adrian, T.; Schoenmakers, $\mathrm{H}$. Investigation of ethyl acetate reactive distillation process. Chem. Eng. Sci. 2001, 56, 6185.

(32) Kloker, M.; Kenig, E. Y.; Gorak, A.; Markusse, A. P.; Kwant, G.; Moritz, P. Investigation of different column configurations for the ethyl acetate synthesis via reactive distillation. Chem. Eng. Process. 2004, 43, 791.

(33) Tang, Y. T.; Chen, Y. W.; Huang, H. P.; Yu, C. C.; Hung, S. B.; Lee, M. J. Design of reactive distillations for acetic acid esterification. AIChE J. 2005, 51, 1683.

(34) Smejkal, Q.; Kolena, J.; Hanika, J. Ethyl acetate synthesis by coupling of fixed-bed reactor and reactive distillation column-Process integration aspects. Chem. Eng. J. 2009, 154, 236.

(35) Kreis, P.; Gorak, A. Process analysis of hybrid separation processes combination of distillation and pervaporation. Chem. Eng. Res. Des. 2006, 84, 595.

(36) Baker, R. W.; Wijmans, J. G.; Huang, Y. Permeability, permeance and selectivity: A preferred way of reporting pervaporation performance data. J. Membr. Sci. 2010, 348, 346.

(37) Kariduraganavar, M. Y.; Kulkarni, S. S.; Kittur, A. A. Pervaporation separation of water-acetic acid mixtures through poly(vinyl alcohol)-silicone based hybrid membranes. J. Membr. Sci. 2005, 246, 83.

(38) Aminabhavi, T. M.; Naik, H. G. Synthesis of graft copolymeric membranes of poly(vinyl alcohol) and polyacrylamide for the pervaporation separation of water/acetic acid mixtures. J. Appl. Polym. Sci. 2002, 83, 244.

(39) Teli, S. B.; Gokavi, G. S.; Sairam, M.; Aminabhavi, T. M. Highly water selective silicotungstic acid $\left(\mathrm{H}_{4} \mathrm{SiW}_{12} \mathrm{O}_{40}\right)$ incorporated novel sodium alginate hybrid composite membranes for pervaporation dehydration of acetic acid. Sep. Purif. Technol. 2007, 54, 178.

(40) Li, G.; Kikuchi, E.; Matsukata, M. A study on the pervaporation of water-acetic acid mixtures through ZSM-5 zeolite membranes. J. Membr. Sci. 2003, 218, 185.

(41) Chen, Y. W.; Xiangli, F. J.; Jin, W. Q.; Xu, N. P. Organicinorganic composite pervaporation membranes prepared by selfassembly of polyelectrolyte multilayers on macroporous ceramic supports. J. Membr. Sci. 2007, 302, 78. 